\title{
BRONQUIOLITIS OBLITERANTE COMO SECUELA DE INFECCIÓN POR ADENOVIRUS. PRESENTACIÓN DE CASO, HOSPITAL INFANTIL DR. ROBERT REID CABRAL
}

\section{Bronchiolitis Obliterans as sequel of Adenovirus infection. Case report, Hospital Infantil Dr. Robert Reid Cabral}

\section{Leandra Cordero Oñate ${ }^{a}$, Madeline Santana Jiménez ${ }^{\mathrm{b}}$ y Sofía Vásquez Pérez}

Recibido: 6 de noviembre, 2019 • Aprobado: 20 de diciembre, 2019

Cómo citar: Cordero Oñate L, Santana Jiménez M, Vásquez Pérez S. Bronquiolitis Obliterante como secuela de infección por Adenovirus. Presentación de caso, Hospital Infantil Dr. Robert Reid Cabral. cysa [Internet]. 15 de junio de 2020 [citado 17 de junio de 2020];4(2):109-114. Disponible en: https://revistas.intec.edu.do/index.php/cisa/article/view/1755

\section{Resumen}

Los procesos pulmonares en menores de dos años son causados en su mayoría por agentes virales, los cuales, en gran parte, se resuelven sin complicaciones posteriores. Sin embargo, hay agentes causales que debemos tener presentes puesto que pueden dejar secuelas importantes a nivel pulmonar. A continuación, presentamos un caso de bronquiolitis obliterante como secuela de infección por adenovirus.

Palabras clave: bronquiolitis obliterante; adenovirus; neumología; vidrio esmerilado; sibilantes; postinfecciosa.

\footnotetext{
a Departamento de Neumología Pediátrica Hospital Infantil Dr. Robert Reid Cabral, República Dominicana. ORCID: 0000-0002-5566-5929 Correo-e: dra.cordero.onate@gmail.com

b Residente de Pediatría Hospital Infantil Dr. Robert Reid Cabral, República Dominicana. ORCID: 0000-0003-4705-8544

Correos-e: madelinesj@gmail.com,m.santana5@unibe.edu.do
}

\begin{abstract}
Pulmonary processes in children under two years are mostly caused by viral agents, which are largely resolved without further complications, however there are causal agents that we must keep in mind that can leave important sequelae at the lungs. We present a case of Bronchiolitis Obliterans as sequel of Adenovirus infection.
\end{abstract}

Keywords: Bronchiolitis obliterans; adenovirus; neumology; ground glass; wheezing; postinfectious.
${ }^{\mathrm{c}}$ Residente de Pediatría Hospital Infantil Dr. Robert Reid Cabral, República Dominicana. ORCID: 0000-0001-5166-6767

Correo-e: sofia_marlene23@gmail.com 


\section{Introducción}

La bronquiolitis obliterante (BO) es una enfermedad pulmonar obstructiva crónica, infrecuente que afecta a los bronquiolos y a las vías respiratorias de menor calibre. Se produce una agresión del aparato respiratorio inferior que causa fibrosis de las vías respiratorias pequeñas. En los pacientes no trasplantados la $\mathrm{BO}$ es más frecuente en niños tras una infección respiratoria (particularmente por adenovirus, aunque también puede estar producida por mycoplasma, sarampión, legionella, gripe y tos ferina).

\section{Reporte de caso}

Paciente femenina de un (1) año la cual es llevada al área de emergencias de un centro de salud de su comunidad tras presentar tos, fiebre y dificultad respiratoria. Es tratada de manera ambulatoria como amigdalitis. Al ver persistencia del cuadro es llevada nuevamente e ingresada como absceso periamigdalino y proceso bronquial obstructivo. Es tratada con antibióticos, clindamicina, ceftriaxona, luego se agrega a la terapia nebulizaciones y esteroides inhalados no especificados, sin mejoría del cuadro. Entre las pruebas complementarias indicadas: hemograma con leucocitosis y una radiografía de tórax (imagen 1).

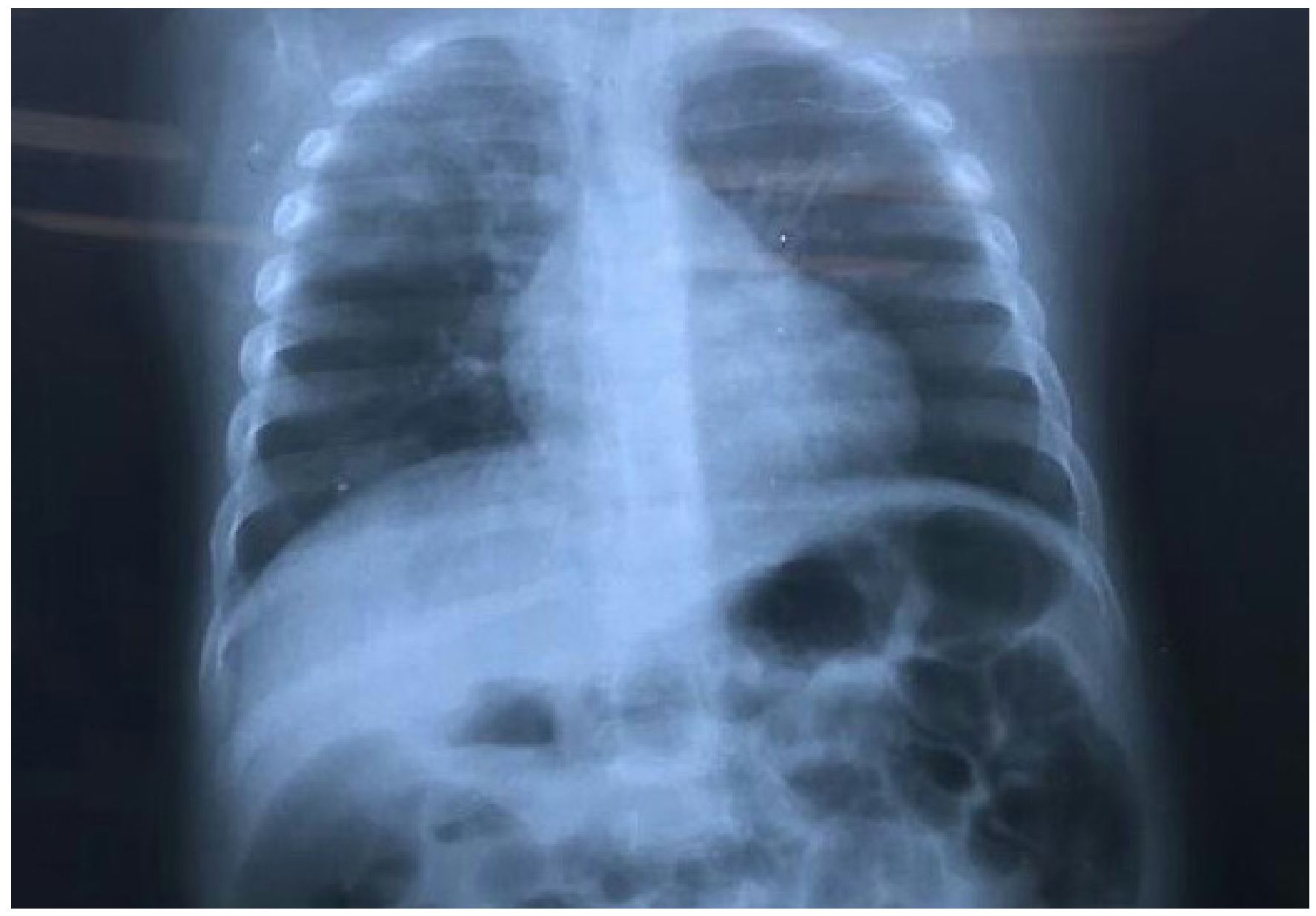

Imagen 1. Radiografía de tórax: reforzamiento de la trama parahiliar bilateral. Elevación de hemidiafragma derecho sugestivo de atelectasia $^{1}$

Fuente: imagen extraída de récord del paciente, del Departamento de Archivo HIRRC. 
Luego de 14 días de ingreso presenta un cuadro de cianosis generalizada y desviación de la mirada. Se administra diazepam durante el episodio. Es referida a nuestro centro y es ingresada en la Unidad de Cuidados Intensivos, donde permaneció durante una semana bajo tratamiento. Durante su estadía se indica una tomografía de tórax (imagen 2). Tras mejoría del cuadro es trasladada a sala clínica donde presentó buena evolución del cuadro clínico y fue egresada con manejo ambulatorio.
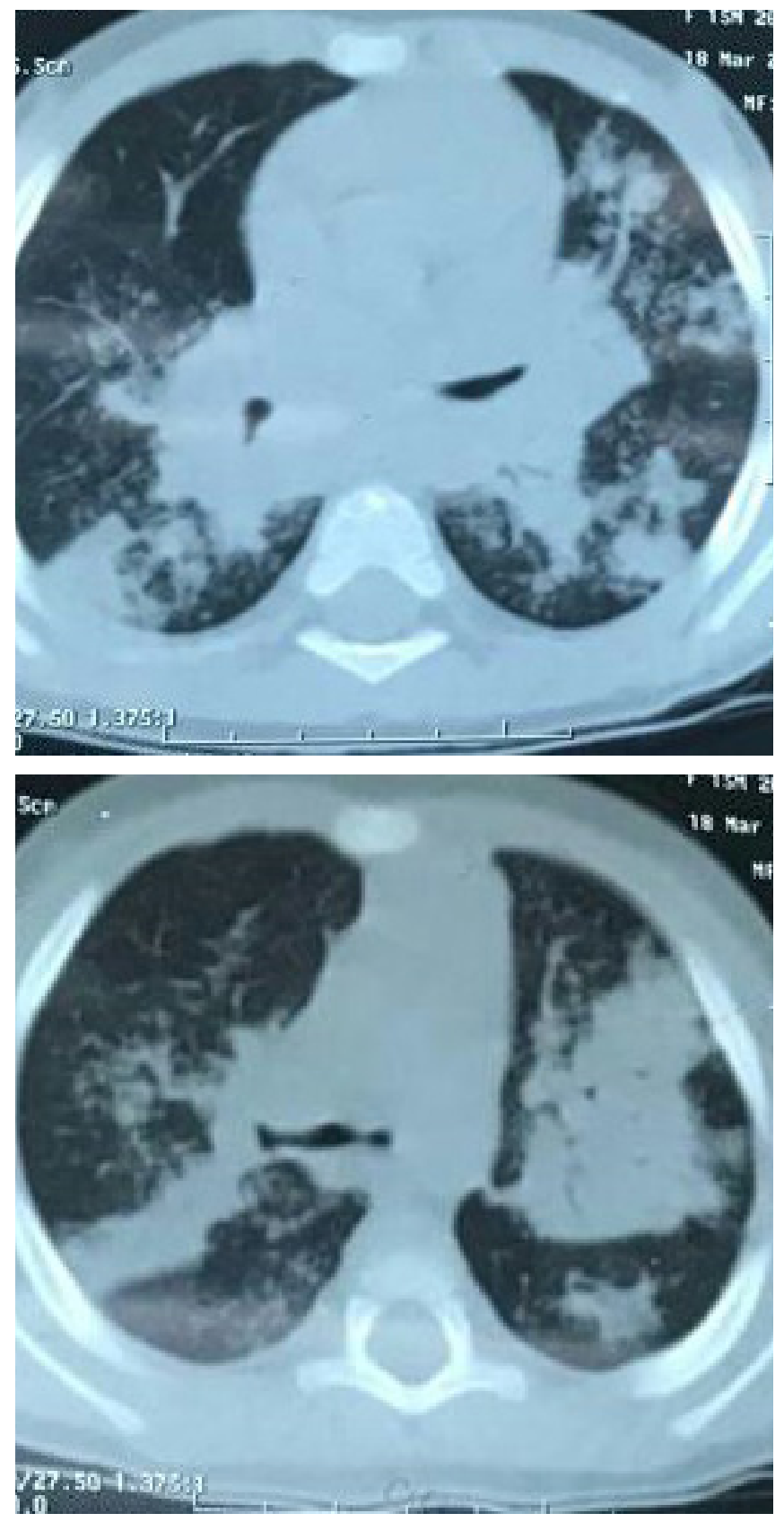

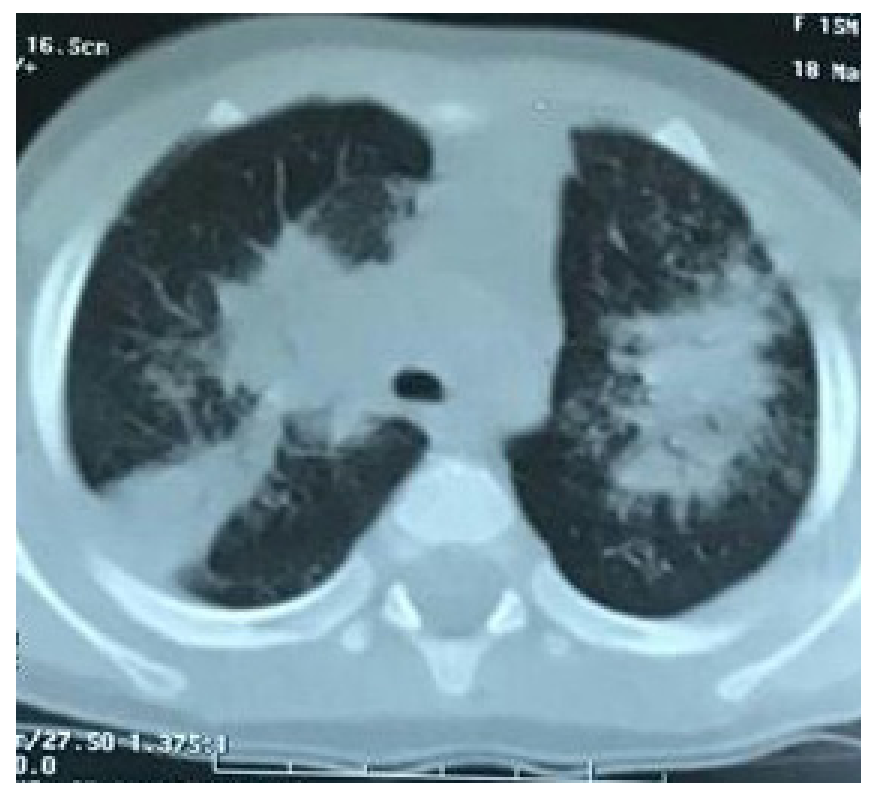

Imagen 2. Tomografía de tórax: opacidades en vidrio esmerilado y consolidaciones con broncograma aéreo correlacionados con el proceso neumónico de la paciente ${ }^{1}$

Fuente: imagen extraída del récord de paciente. Departamento de Archivo HIRRC.

Ante la sospecha clínica de un agente causal atípico se indica un Panel Respiratorio que se envía al exterior, los resultados fueron llevados a consulta y confirmaron la presencia de un adenovirus (tabla 1).

Tabla 1. Resultado de panel respiratorio de la paciente

\begin{tabular}{|c|c|c|}
\hline Panel viral & Resultados & Rango \\
\hline $\begin{array}{c}\text { Adenovirus } \\
\text { AB, CF }\end{array}$ & $>1: 64$ & $<1: 8$ \\
\hline
\end{tabular}

Fuente: resultado extraído de récord del paciente. Departamento de Archivo HIRRC.

Actualmente, la paciente tiene dos años y es seguida por el Departamento de Neumología Pediátrico, con diagnóstico de Bronquiolitis Obliterante por secuela de infección por adenovirus, ha tenido varios reingresos por dificultad respiratoria y disminución de la oximetría de pulso. 


\section{Discusión}

La bronquiolitis obliterante es una neumopatía rara, que se produce como consecuencia de una agresión grave a la vía aérea inferior y que ocasiona un estrechamiento y/o una obliteración completa de las vías respiratorias más pequeñas. En pediatría, la forma más común de $\mathrm{BO}$ es la postinfecciosa, (BOPI). Aunque se han descrito casos de BOPI secundarios a virus influenza, parainfluenza, sarampión, virus respiratorio sincitial (VRS) y Mycoplasma pneumoniae, el adenovirus es el agente infeccioso implicado con más frecuencia. ${ }^{2,3}$

La $\mathrm{BO}$ se produce en todos los grupos de edad, y la prevalencia fue del 2 por 1.000 en una serie de autopsias pediátricas. Hay algunos datos de que la $\mathrm{BO}$ postinfecciosa puede ser más frecuente en el hemisferio sur y en personas de origen asiático.

La etiología de la $\mathrm{BO}$ es muy variada. En los países desarrollados se presenta principalmente como una complicación del trasplante pulmonar, ${ }^{4}$ en los países en vías de desarrollo se debe mayormente a una infección viral. Entre las principales causas se encuentran agentes infecciosos, enfermedades autoinmunes o vasculitis, inhalación o ingesta de tóxicos o trasplante de médula ósea o pulmonar. Entre los agentes infecciosos destaca el adenovirus, particularmente los serotipos 3, 7, 11, 1, 5 y 21 aunque en el caso de nuestra paciente se identificó el adenovirus $\mathrm{AB}, \mathrm{CF}$. Los tres primeros han sido especialmente descritos en los pacientes afectos de BO en América del Sur. Otros microorganismos descritos han sido herpes simple, virus parainfluenza tipo 3, virus de la inmunodeficiencia humana $(\mathrm{VIH})$, citomegalovirus (especialmente en pacientes con trasplante pulmonar), VRS, Mycoplasma y B. pertussis. Entre los agentes tóxicos inhalados destacan el óxido de nitrógeno, el amoniaco y el zumo de Sauropus androgynus. Se estima que la BO, per se, afecta al $10 \%$ de todos los receptores de trasplante de médula ósea (TMO) que desarrollan enfermedad de injerto contra huésped crónica (EICH). ${ }^{5}$
Las formas graves de infección por adenovirus 3 , 7 y 21 necrosan el tejido alveolar y bronquiolar. Se conoce que algunos grupos raciales (polinesios, neozelandeses y nativos canadienses) presentan una sensibilidad particular a los adenovirus, fenómeno para el que se han invocado factores genéticos y ambientales. En las últimas dos décadas, los países de América del Sur han acumulado un gran número de pacientes afectos de $\mathrm{BO}$. Parece que la composición racial pudiera ser un factor de riesgo para el desarrollo de $\mathrm{BO}$ y así, un grupo argentino ha descrito en sus pacientes afectos de $\mathrm{BO}$ la elevada presencia de un alelo, ampliamente descrito en población amerindia (HLA DR8-DQB1*0302). ${ }^{2}$

La lesión necrosante de la infección aguda de esta etiología se sigue de un proceso de reparación con fibrosis y obstrucción de las pequeñas vías aéreas. El $60 \%$ de los nińos con infección por adenovirus demostrada desarrollan enfermedad pulmonar crónica. Las dos secuelas más llamativas son la hiperinsuflación generalizada y el síndrome del pulmón hiperlucente unilateral, es decir, el síndrome de McLeod o síndrome de Swyer-James-Mac Leod. El pronóstico individual de cada paciente está relacionado con diversos factores, entre ellos el tiempo de requerimiento de oxígeno y la gravedad de las reinfecciones respiratorias. ${ }^{6}$

Actualmente, la $\mathrm{BO}$ se diagnostica de acuerdo con antecedentes de lesiones en el tracto respiratorio inferior, generalmente infecciones y síntomas persistentes que no responden a la administración de corticoides sistémicos y broncodilatadores durante dos semanas, o respuesta parcial a los mismos, ${ }^{7}$ hallazgos tomográficos (TAC) y exclusión de otras enfermedades. Los factores epidemiológicos, el tratamiento y el pronóstico de la enfermedad deben definirse más claramente para reducir la morbilidad y la mortalidad.

Los hallazgos de la radiografía de tórax más frecuentes de pacientes con $\mathrm{BO}$ son: engrosamiento 
peribronquial, hiperinflación pulmonar, atelectasia, opacidad alveolar, pulmón pequeño o hiperlucido y áreas hiperlucidas localizadas. Tanto los hallazgos radiográficos como tomográficos de nuestra paciente son compatibles con los descritos en la literatura. ${ }^{8}$

La BO post infecciosa usualmente ocurre en niños menores de 12 meses. Inicialmente, durante el ingreso hospitalario, presentan síntomas que no difieren de la bronquiolitis severa, la mayoría evidencian obstrucción severa de las vías respiratorias con hipoxemia y en muchos casos requieren ventilación mecánica. ${ }^{6}$

Una vez establecida la $\mathrm{BO}$ se caracteriza clínicamente por taquipnea, aumento del diámetro anteroposterior del tórax, crepitante, sibilancias e hipoxemia durante al menos 30 días después de la lesión inicial. ${ }^{9}$

Muchos factores de riesgo pueden llevar al desarrollo de la bronquiolitis obliterante. Entre las causas no infecciosas, la más importante es luego del trasplante renal y el trasplante de células hematopoyéticas. Se presenta además luego de la inhalación de toxinas como el diacetilo, presente en el saborizante de palomitas, en este caso siendo una enfermedad ocupacional en los trabajadores en fábricas de palomitas de maíz para microondas. ${ }^{10}$ Otras causas son las enfermedades autoinmune como artritis reumatoide. En los niños las causas infecciosas siguen siendo las más comunes. ${ }^{11}$

La bronquiolitis obliterante de causa no infecciosa ha cobrado importancia por ser la lesión que es causada por los cigarrillos electrónicos (e-cigarettes) y el vaping, también llamado "pulmón de palomita de maíz". Aún se desconoce la totalidad del impacto en los pulmones de los cigarrillos electrónicos. ${ }^{12}$

La bronquiolitis obliterante es un proceso que implica cicatrización de las vías aéreas pequeñas y que resulta en una enfermedad pulmonar obstructiva irreversible. ${ }^{13}$

Entre los tratamientos a largo plazo que aún están en etapa de prueba es el uso de cortioesterides intravenosos a modo de pulsos, con fines de evitar los efectos secundarios de corticoesteroides vía oral, tanto en niños cuya que la desarrollaron secundaria a infección viral, como en aquellos que fue secundario a transplante. ${ }^{14,15}$

\section{Conclusión}

La bronquiolitis obliterante es una complicación rara de procesos virales y es una causa importante de morbi-mortalidad por lo que se debe tener entre los diagnósticos diferenciales en procesos respiratorios persistentes sin mejoría del cuadro.

\section{Bibliografía}

1. Comité Nacional de Neumonología. Bronquiolitis obliterante posinfecciosa. Arch Argent Pediatr 2018;116(Supl 3):S48-S58.

2. Velasco González V, Delgado Pecellín I, Selva Folch B. Bronquiolitis obliterante. Protoc diagn ter pediatr. 2017;1:115-26.

3. González R. Adenovirus: de la Neumonía a la Bronquiolitis Obliterante. Neumol Pediatr. 2019;14(1):19-22. Disponible en https:// www.neumologia-pediatrica.cl/wp-content/ uploads/2019/05/4.pdf

4. García Rojas VA, Mora Hernández GA. Bronquiolitis Obliterante. Revista Médica de Costa Rica y Centroamérica. 2016;620:475-8.

5. Colom, AJ, Teper, AM, Vollmer, WM y Diette, GB. Factores de riesgo para el desarrollo de bronquiolitis obliterante en nińos con bronquiolitis. Tórax. 2006;61(6),503-6. Disponible en https://doi.org/10.1136/thx.2005.044909 
6. Colom AJ. Función pulmonar en bronquiolitis obliterante post infecciosa. Neumología Pediátrica. 2019;14(1):29-33.

7. Nayar S, Escobar AM. Función pulmonar y calidad de vida en nińos y adolescentes con bronquiolitis obliterante por adenovirus. Revista Chilena de Enfermedades Respiratorias. 2011; 27:191-5.

8. Lino CA, Batista AKM, Soares MAD, Freitas ÂE, Gomes LC, M. Filho JH, Gomes VC. Bronchiolitis obliterans: clinical and radiological profile of children followed-up in a reference outpatient clinic. Revista Paulista de Pediatria. 2013;31(1):10-6. Available from: https://dx.doi. org/10.1590/S0103-05822013000100003

9. Boas SR. Nelson, Tratado de pediatría: bronquiolitis obliterante (19a ed., Vol. 1). España: Elsevier Inc; 2013.

10. Krishna R, Tony IO. Bronchiolitis Obliterans (Obliterative Bronchiolitis, Constrictive Bronchiolitis). Nih.Gov, StatPearls Publishing, 11 Nov. 2019, [internet]. Available from www.ncbi. nlm.nih.gov/books/NBK441865/.
11. Cruz M. Nuevo Tratado de Pediatría: Broquiolitis (2a ed., Vol. 2). Barcelona: Océano. $10 ; 2011$.

12. Landman ST, et al. Life-Threatening Bronchiolitis Related to Electronic Cigarette Use in a Canadian Youth. Canadian Medical Association Journal. 2019;191(48):E1321-E1331. Available from: www.cmaj.ca/content/191/48/ E1321, 10.1503/cmaj.191402.

13. Centro Médico de la Universidad de Pittsburgh. Revisión del Centro Médico de la Universidad de Pittsburgh; 2019.

14. Ratjen F, Rjabko O, Kremens B. High-dose corticosteroid therapy for bronchiolitis obliterans after bone marrow transplantation in children. Bone Marrow Transplant. 2005;36:135-8 Available from https://doi.org/10.1038/sj.bmt.1705026

15. Tomikawa SO, Adde FV, da Silva Filho LVRF et al. Follow-up on pediatric patients with bronchiolitis obliterans treated with corticosteroid pulse therapy. Orphanet J Rare Dis. 2014;9:128. Available from https://doi.org/10.1186/s13023014-0128-2 